\title{
GENDER MANIFESTATION IN FRENCH ADVERTISING SLOGAN
}

\author{
(C) 2019 Golovanova Irina Sergeevna \\ Candidate of Philology, Associate Professor \\ (c) 2019 Kapustina Liubov Viktorovna \\ Candidate of Pedagogy, Associate Professor \\ (C) 2019 Martynova Irina Anatolevna \\ Candidate of Philology, Associate Professor \\ Samara State University of Economics \\ E-mail: irgolovanova@yandex.ru
}

Keywords: gender, advertising, advertising slogan, French.

The paper deals with the advertising slogan that is the relevant aspect for creating image of modern companies. The French advertising slogan has its own characteristics: it is beautiful, elegant and attractive. It reflects the national characteristics of aesthetic perception. The slogan carries imprint of the gender factor due to the fact that advertising is always aimed at a certain audience. The aim of the study is to analyze the language features of French advertising constructions on the basis of gender differences. The research is based on advertising slogans from French periodicals.

УДК 811

Код РИНЦ 16.00.00

ЛЕКСИЧЕСКОЕ СХОДСТВО АНГЛИЙСКОГО И НЕМЕЦКОГО ЯЗЫКОВ

\author{
(C) 2019 Ефремова Юлия Ивановна \\ кандидат филологических наук, доцент \\ (с) 2019 Петрянина Ольга Валерьевна \\ кандидат филологических наук, доцент \\ Самарский государственный экономический университет \\ E-mail: yul-efrem@yandex.ru, petryaninaolga@rambler.ru
}

Ключевые слова: этимология, индоевропейская группа, заимствования, лексика.

В статье выявлены и продемонстрированы основные сходства и отличия слов, установлены причины их возникновений. Определена этимология некоторых похожих английских и немецких слов.

Актуальность данной статьи заключается в том, что английский и немецкий языки широко распространены в Российских вузах, имеют практически одинаковое распространение в мировом сообществе с точки зрения экономических и политических связей. Данная статья позволит студентам и всем желающим, изучающим один иностранный язык нацелиться на изучение второго иностранного языка и стереть стереотип сложности изучения языков. 
Цель данной работы: выявить и продемонстрировать наличие сходств слов и их причины возникновений в английском и немецком языках.

Задачи:

- изучить историю английского и немецкого языков;

- выяснить этимологию некоторых похожих английских и немецких слов.

Язык - это инструмент общения, благодаря которому происходит взаимодействие между людьми.

На языке говорили задолго до того, как люди начали писать. Языки постоянно претерпевают изменениям. Слова отбрасываются, новые слова развиваются, некоторые адаптированы из других языков, и значения слов меняются со временем.

Bсе языки разработаны на основе общих языковых семей, которые заметны на ранних стадиях языков. Немецкий и английский являются частью одной языковой семьи, называемой "индоевропейской", которое включает в себя большинство европейских языков, а также персидский, санскрит и урду. Исторически немецкий и английский происходили из одной языковой семьи, западно-германской группы. Таблица 1 иллюстрирует общие элементы, которые все еще существуют между языками.

Таблица 1

Общие элементы языков германской группы ${ }^{1}$

\begin{tabular}{|c|c|c|c|c|}
\hline Немецкий & Голландский & Шведский & Датский & Английский \\
\hline Erde & aarde & jord & jord & earth \\
\hline Feld & veld & fält & mark & field \\
\hline Frost & vorst & frost & frost & frost \\
\hline Gras & gras & gräs & graes & grass \\
\hline Licht & licht & ljus & lys & light \\
\hline Schnee & sneeuw & snö & sne & snow \\
\hline Welt & wereld & värld & verden & world \\
\hline Wetter & weer & väder & vejr & weather \\
\hline
\end{tabular}

Под индоевропейским элементом понимаются слова, являющиеся общими для всех или большинства языков индоевропейской группы. Слова этой группы репрезентируют элементарные понятия, однако без них невозможно общение. Можно выделить следующие группы:

Таблица 2

Сравнение английских и немецких слов²

\begin{tabular}{|c|c|c|}
\hline & Английский & Немецкий \\
\hline семейные отношения & father, mother, brother & Vater, Mutter, Bruder \\
\hline части тела & foot, nose, lip, & Fuß, Nase, Lippen, \\
\hline животные & cow, swine, goose & Kuh, Schwein, Gans \\
\hline Растения & birch, mais & Birke, Mais \\
\hline времена суток & day, night & Tag, Nacht \\
\hline небесные тела & Sun, moon, star & Sonne, Mond, Sterne \\
\hline Нумерация от 1 до 100 & one, two, three...hundred & ein, zwei, drei, vier ... hundert \\
\hline Большое количество глаголов & stand, sit, eat & Ständer, sitzen, essen \\
\hline
\end{tabular}


Учитывая общие корни двух языков, неудивительно, что словари современного немецкого и английского имеют много общего. Например: house/Haus, man/Mann, here/hier, good/gut. Было подсчитано, что приблизительно 35\% нетехнических лексиконов и большинство наиболее часто используемых слов в английском языке имеют германское происхождение. Поскольку эти два языка когда-то были одинаковыми, грамматика английского и немецкого языков очень похожа. Все, что мы находим трудным в современном немецком языке, от падежей до структуры предложения, все это когда-то существовало в английском языке. Однако он утратил довольно много этих грамматических правил за последние несколько сотен лет. Тем не менее, если знать, что глагол нерегулярен в английском языке, он почти всегда нерегулярен и в немецком. Например, английский глагол "плавать" - swim - swam - swum, в Германии, это schwimmen- schwamm geschwommen. Это, очевидно, не совсем то же самое, но если сравнить его с романским языком, таким как испанский (nadar - nadé - nadado), то можно увидеть, что английский язык немного ближе к немецкому, чем испанский.

Чтобы понять, как английские слова используются в немецком языке, и как они изменяются, чтобы адаптироваться к нему, необходимо получить представление о наиболее важных различиях между двумя участвующими языками.

Если английское слово входит в немецкий словарный запас, оно не всегда сохраняет свое первоначальное значение и форму. Поскольку английский и немецкий языки отличаются своей грамматикой и морфологией, англицизмы часто адаптируются к немецкому языку в их орфографии и флексии. В то же время некоторые правила английского языка переносятся на немецкий. Различия между английским и немецким языками, которые играют наибольшую роль в этом исследовании, можно найти, в частности, в неравной морфологии. Так, например, в английском языке, как правило, достаточно инфинитива глагола, чтобы все лица единственного числа, а также множественного числа, выполняли действие. В качестве примера возьмем глагол reden - говорить. В немецком языке спряжение данного глагола оказывается относительно сложным: Ich red e , du red est , er/sie/es red et, wir red en , ihr red et, sie red en. Если рассматривать соответствующий глагол в английском языке, to talk, то, кроме инфинитива, в первом лице единственного числа встречается только одна форма флексии: I talk , you talk, he/she talk s, we talk, you talk, they talk. ${ }^{3}$ Таким образом, английский язык сильно отличается от немецкого языка в грамматике.

Английские заимствованные слова подчиняются некоторым немецким правилам словообразования. Так, например, английские глаголы легче интегрируются, чем существительные, и просто добавляют '-en', такие как killen, testen, dopen. Они всегда спрягаются так же, как слабые (регулярные) глаголы, killte, gekillt. Глагол babysitten используется только в инфинитиве, возможно, для решения проблем о том, является ли он отделимым или нет - было бы абсурдно говорить "ich site eine halbe Stunde baby"! Существительные мужского рода иногда можно преобразовать в женские, добавив к ним префикс in, как y User и Userin. Однако иногда это немыслимо, как, например, при слове Bodyguard телохранитель. Большинство прилагательных, таких как smart, cool, fair, postmodern не вызывают проблем, связанных с их употреблением в немецком языке, 
поскольку они просто добавляют соответствующие окончания прилагательных, например ein Fair Angebot. Но некоторые прилагательные не фрлексируют, так как они в основном встречаются в предикативной позиции.

Английский язык заимствовал ряд слов из немецкого языка, и некоторые из них используются довольно регулярно. Например, слово "рюкзак" для описания сумки, которую несут на спине человека, или слово "тоска", используемое в психологии для описания тревоги.

Использование немецких слов в английском языке еще более распространено, когда речь заходит о еде и напитках. Слово "спритцер" (яблоко) часто используется, когда речь заходит об алкоголе, в то время как "крендель", "штрудель" и "братвурст" тоже являются немецкими. Между тем, английский язык также заимствовал слово "delicatessen" для описания магазинов, продающих предварительно приготовленные продукты. ${ }^{4}$

На протяжении многих лет немецкий язык также заимствовал ряд английских слов. Это особенно распространено в мире технологий, музыки, рекламы и моды, где носители английского языка должны столкнуться с большим количеством знакомых слов и фраз при переходе на немецкий язык.

Например, слова "компьютер", "дизайнер", "альбом", "изображение" и "лазер" были заимствованы из английского языка, и английские слова часто заимствованы, когда увлечение начинается за пределами немецкоязычных областей. Примеры этого включают "скейтбординг" и "аэробика", которые оба признаны немецкими носителями.

В дополнение к огромному количеству слов, которые разделяются между двумя языками, немецкий и английский также имеют много слов, которые звучат очень похоже. Это главный плюс, когда речь заходит об изучении немецкого языка с точки зрения понимания английского языка, так как часто можно догадаться, что означают некоторые слова.

Например, немецкое слово " дом "означает " Наus", немецкое слово "университет" "Universität", а немецкое слово "камера" - "Kamera". Для англоговорящего было бы довольно легко установить, что немецкое предложение "Ich trinke Wasser" означает "Я пью воду", даже если они никогда раньше не сталкивались с этими немецкими словами. ${ }^{5}$

Другая категория - это названия месяцев. Причина, по которой так легко идентифицировать немецкие месяцы, заключается в том, что они все пришли с латыни, как и английские термины.

Таблица 3

Заимствование латинских слов ${ }^{6}$

\begin{tabular}{|c|c|c|}
\hline Латынь & Немецкий & Английский \\
\hline presbyter & Priester & priest \\
\hline monachus & Mönch & monk \\
\hline nonna & Nonne & nun \\
\hline Candela & Kerzen & candle \\
\hline schola & Schule & school \\
\hline magister & Magiste & magister \\
\hline
\end{tabular}


Было важно, чтобы германские языки получили значительное количество новых слов для обогащения своего собственного. В седьмом веке нашей эры распространение христианства привело к заимствованию новых латинских слов, связанных с церковными и религиозными обрядами. Кроме того, первыми школами в Англии были церковные школы, а первыми учителями были священники и монахи.

Исторический обзор выше далек от завершения. Однако он дает самое общее представление о возникновении сходств английского и немецкого языков.

Анализируя языковые явления на конкретных примерах, можно сказать, что немецкий и английский языки имеют много сходств в лексике. Оба языка располагают словами внешне похожими друг на друга с одинаковыми значениями. Сходство в языке - не единственное преимущество. Похожая культура, ценности, еда и напитки также могут сделать обучение и интеграцию легкими и интересными.

${ }^{1}$ Красухин, К.Г. История английского языка и введение в германскую филологию: Краткий очерк: учеб.-метод. пособие / К.Г. Красухин. - М.: Флинта, 2016. - 104 с.

2 Там же.

${ }^{3}$ Хроленко, А.Т. Введение в филологию: Учебное пособие / А.Т. Хроленко. - М.: Флинта, 2015. - 252 c.

${ }^{4}$ Солопов, А.И. Латинский язык 3-е изд., пер. и доп. учебник и практикум для академическогобакалавриата / А.И. Солопов, Е.В. Антонец. - Люберцы: Юрайт, 2016. - 458 с.

${ }_{5}^{5}$ Рождественсий, Ю.В. Введение в общую филологию / Ю.В. Рождественсий. - М.: Высшая школа, 2015. - 224 с.

${ }_{6}^{6}$ Гак, В.Г. Введение во французскую филологию: Учебник и практикум для академическогобакалавриата / В.Г. Гак, Л.А. Мурадова. - Люберцы: Юрайт, 2016. - 303 с.

\section{LEXICAL SIMILARITIES BETWEEN ENGLISH AND GERMAN}

(c) 2019 Efremova Yuliya Ivanovna

Candidate of Philological Sciences, Associate Professor

(C) 2019 Petryanina Ol'ga Valer'evna

Candidate of Philological Sciences, Associate Professor

Samara State University of Economics

E-mail: yul-efrem@yandex.ru, petryaninaolga@rambler.ru

Keywords: etymology, Indo-European group, borrowings, vocabulary.

The article identifies and demonstrates the main similarities of words and the causes of their occurrence. The etymology of some similar English and German words is defined. 